\title{
The need for, and utilization of prostate-bed radiotherapy after radical prostatectomy for patients with prostate cancer in British Columbia
}

\author{
Scott Tyldesley, MD, FRCPC; ${ }^{*}$ Michael Peacock, MD;* James W. Morris, MD, FRCPC; MD; ${ }^{*}$ Alan So, MD,

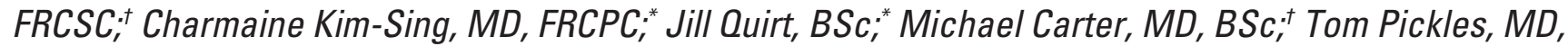 \\ FRCPC
}

*Department of Radiation Oncology, Vancouver Cancer Centre, BC Cancer Agency, Vancouver, BC; 'Department of Urologic Sciences, University of British Columbia, Vancouver, BC

See related article on page 95 .

Cite as: Can Urol Assoc J 2012;6(2):89-94. http://dx.doi.org/10.5489/cuaj.11158

\section{Abstract}

Introduction: Three randomized trials have demonstrated that post-radical prostatectomy $(\mathrm{RP})$ radiotherapy decreases biochemical relapse for those with adverse pathology. Our purpose was to describe the incidence of pathologic risk factors for recurrence in a contemporary series of patients treated with RP and to describe the use of post-RP radiotherapy.

Methods: All incident prostate cancers diagnosed between January 2005 and December 2007 were identified from the tumour registry. Cases were then linked to radiotherapy records which included dose and modality (external beam radiotherapy and brachytherapy). The pathology reports in the tumour registry were reviewed for pathologic stage, grade and margin status.

Results: We identified 9223 patients with prostate cancer. Overall, $36.3 \%$ of patients treated with RP had positive margins, and may have benefited from adjuvant radiotherapy. After RP, 332 (15\%) patients had radiotherapy to the prostate bed; of these, only 25 $(1.1 \%)$ received truly adjuvant radiotherapy (delivered within 6 months with a prostate-specific antigen of $<0.2 \mathrm{ng} / \mathrm{mL}$ ). Of the 2181 patients treated with RP, $270(12 \%)$ were seen by a radiation oncologist within 6 months of RP. Of the 1015 patients (47\%) with adverse RP pathology (positive margins, extracapsular extension or seminal vesicle invasion), $230(23 \%)$ were seen by a radiation oncologist within 6 months of RP.

Conclusion: Not all patients with adverse prostatectomy pathology were seen by a radiation oncologist post-prostatectomy, and very few received adjuvant radiotherapy despite almost half of them having risk factors for relapse.

\section{Introduction}

Starting in 2004, three randomized trials reported on the role of post prostatectomy radiotherapy for prostate cancer patients with adverse pathology (positive margins, extraca- psular extension [ECE] or seminal vesicle invasion [SVI]). ${ }^{1-3}$ All three demonstrated a significant reduction in the rate of biochemical relapse with the use of early postoperative radiotherapy compared to initial observation. In 2009, Thompson and colleagues, for the first time, demonstrated that this biochemical disease-free survival advantage translated into an overall survival and disease-specific survival advantage at 10 years. ${ }^{4}$ Updates from a subgroup analysis of the European trial and from the German trial suggested that the benefit of postoperative adjuvant radiotherapy may be confined to patients with positive margins. ${ }^{5,6}$ In addition, there is debate as to whether early salvage at the time of first detection of prostate-specific antigen (PSA) provides an outcome equivalent to truly adjuvant radiotherapy. ${ }^{7,8}$

On the basis of the initial trial results, the Canadian Genitourinary Radiation Oncology group published two consensus statements on the use of postoperative adjuvant and salvage radiotherapy in the Canadian Urological Association Journal (CUAJ).9,10 With respect to the role of adjuvant radiotherapy, the consensus statement recommended that "consultation with a radiation oncologist early in the postoperative period is advised to discuss benefits and side effects of adjuvant radiotherapy in those with adverse pathological features at prostatectomy," and that "patients should be offered adjuvant external beam radiotherapy (within 6 months of surgery)." ${ }^{\prime 9,10}$

Cancer Care Ontario's Surgical Oncology program recently reported on evidence-based quality indicators for radical prostatectomy (RP) in prostate cancer management. ${ }^{11}$ The panel "unanimously determined that the goals for RP are to attain a positive margin rate of $<25 \%$ for pT2 disease, a mortality rate of $<1 \%$." 11

Our objective was to describe the population-based utilization of RP and to examine the utilization rate of prostate-bed radiotherapy after RP, and factors predicting its use in British Columbia, in the first few years after the aforementioned randomized trials were published. 
Tyldesley et al.

\section{Methods}

The British Columbia Cancer Agency (BCCA) captures registry and radiotherapy data on all incident cases of prostate cancer diagnosed in British Columbia (BC). All radiotherapy, including brachytherapy and external beam radiotherapy, delivered in BC is delivered at BCCA cancer centres and captured in these databases. All pathology reports from RP specimens with prostate cancer in $\mathrm{BC}$ are captured in the $\mathrm{BC}$ Cancer Registry (BCCR). For patients referred to the BCCA, pre-treatment clinical stage, initial PSA and biopsy Gleason score are recorded. All medical hormonal therapies (such as nonsteroidal anti-androgens and luteinizing hormonereleasing hormone agonists) are recorded in the BCCA pharmacy database.

All incident prostate cancers diagnosed between January 2005 and December 2007 were identified from the BCCR. Radiotherapy and BCCA stage and demographic records were linked to these incident cases. The pathology records in the BCCR were reviewed for pathologic stage, ECE, SVI, margin status, lymph node status and date of surgery for all cases that potentially could have been treated with RP. The registry files were not reviewed for prostatectomy pathology on patients who presented with clinical M1 disease or were known to have been treated with prostate brachytherapy or dose-escalated radiotherapy above 70 Gy (as they are not prescribed post-prostatectomy in $\mathrm{BC}$ ). Palliative RPs done in the setting of clinical M1 presentation and salvage postradiotherapy prostatectomies are not included. No patients were excluded from the analysis; all incident cases diagnosed in the province between January 2005 and December 2007 and captured in the tumour registry are included. All prostatectomy cases, other than those with the above-listed indications, and all post-prostatectomy radiotherapy cases are included. Patients diagnosed in the province, but who left the province for treatment with prostatectomy or radiotherapy would not be captured in the database.

The medical records for cases referred to the BCCA after prostatectomy were reviewed for intent of treatment (i.e., adjuvant or salvage), maximum postoperative PSA pre-radiotherapy, perioperative androgen ablation use, and reasons radiotherapy was not given to patients with risk factors. Postoperative RT was classified as adjuvant for the following reasons: if the radiotherapy was given within 6 months of RP, the postoperative PSA was less than the lab detection limit (typically $0.02 \mathrm{ng} / \mathrm{mL}$ ), and no androgen ablation was given prior to prostatectomy or prior to the first available postoperative PSA.

We then calculated the proportion of cases treated with radiotherapy after RP or with adjuvant radiotherapy (as defined above). We also determined the proportion of patients with adverse risk factors (ECE, SVI or positive margins). In these patients, we also noted the use of postoperative and adjuvant radiotherapy in patients with adverse risk factors.

Logistic regression analysis was performed to determine factors (including age, ECE status, SVI, margin status, Gleason score, residence within 2 hour drive of a cancer centre) predicting the use of postoperative radiotherapy.

\section{Results}

We identified 9223 incident cases of prostate cancer between 2005 and 2007. Of these patients, initial therapy was hormone therapy alone in $1338(14 \%)$, no therapy in $2840(31 \%), \mathrm{RP}$ in $2181(24 \%)$, primary external beam radiotherapy in $2122(23 \%)$ and brachytherapy in $742(8 \%)$ (Table 1). Median ages were 63 years (range: $35-86), 72$ years (range: 47-89) and 65 years (range: 45-81) for those treated with RP, external beam radiotherapy and brachytherapy, respectively. Of the men treated with RP, only $1(0.05 \%)$ died within a month of surgery. The pre-treatment Canadian Consensus risk groups were determined based on available pre-treatment stage, PSA and Gleason score..$^{12}$ Of the 760 RP cases with known pre-treatment risk, $33 \%$ were low risk, $47 \%$ were intermediate risk, and $21 \%$ were high risk. Of the 728 brachytherapy patients with known pre-treatment risk, $36 \%$ were low risk, $57 \%$ were intermediate risk, and $7 \%$ were high risk. Of the 2007 external beam patients with known pre-treatment risk, $10 \%$ were low risk, $42 \%$ were intermediate risk, and $48 \%$ were high risk.

We compared adverse pathologic factors in RP patients

\begin{tabular}{|c|c|c|}
\hline & No. & $\%$ of all* \\
\hline Overall cases of prostate cancer in BC & 9223 & $100 \%$ \\
\hline Number referred to BCCA & 5373 & $58 \%$ \\
\hline \multicolumn{3}{|l|}{ Primary treatment modality } \\
\hline Radical prostatectomy & 2181 & $24 \%$ \\
\hline Primary radical external beam $\mathrm{RT}^{* *}$ & 2122 & $23 \%$ \\
\hline Primary prostate brachytherapy & 742 & $8 \%$ \\
\hline Hormone therapy alone at diagnosisł & 1338 & $14 \%$ \\
\hline No treatment within 12 months of diagnosis & 2838 & $31 \%$ \\
\hline Prostatectomy cases & & $\%$ of $\mathbf{R P}^{\dagger}$ \\
\hline Total cases with adverse pathological features & 1015 & $47 \%$ \\
\hline Positive margins & 793 & $36.3 \%$ \\
\hline Extracapsular extension & 463 & $21.4 \%$ \\
\hline Seminal vesicle involvement & 193 & $9 \%$ \\
\hline Missing pathology & 15 & $0.7 \%$ \\
\hline \multicolumn{3}{|l|}{ Post-radical prostatectomy RT } \\
\hline Salvage $\mathrm{RT}$ post-RP** & 307 & $14 \%$ \\
\hline Adjuvant RT post-RP** & 25 & $1.1 \%$ \\
\hline \multicolumn{3}{|c|}{$\begin{array}{l}\text { BC: British Columbia; BCCA: British Columbia Cancer Agency; RT: radiotherapy; RP: radical } \\
\text { prostatectomy. *Percentage of All, is percentage of all incident cases; } \text { Percentage of } \\
\text { RP is percentage of all radical prostatectomy; **Post RP-RT" means post prostatectomy } \\
\text { radiotherapy. External beam RT subheading excludes post RP-RT. \&This refers to cases that } \\
\text { were started on androgen ablation within } 6 \text { months of diagnosis but did not go on to radical } \\
\text { radiotherapy or radical prostatectomy within } 12 \text { months of diagnosis. }\end{array}$} \\
\hline
\end{tabular}


Need for, and use of, post prostatectomy radiotherapy

with reported rates of adverse pathology from the literature (Table 2, Table 3). ${ }^{13-33}$ Pathologic stages were unknown in $1 \%$, pT2 in $74 \%$, pT3 in $23 \%$ and pT4 in $1 \%$. Overall, $36.3 \%$ of patients treated with RP had positive margins, and would potentially benefit from adjuvant radiotherapy based on level I evidence. However, most patients in the trials had pT3 disease, and in our series only $13 \%$ had both positive margins and pT3 disease (i.e., $57 \%$ had positive margins of the $23 \%$ of cases with pT3 disease). Margins were positive in $30 \%$ of pT2 and $57 \%$ of pT3 patients, and in $49 \%$, $36 \%$ and $32 \%$ of pre-treatment Canadian Consensus high-, intermediate-, and low-risk groups, respectively.

After RP, $332(15 \%)$ patients had radiotherapy to the prostate bed, of these patients only $25(1.1 \%)$ received adjuvant radiotherapy (according to the definition above). Of the patients with any adverse pathology (ECE positive, margin positive or SVI), 290 (29\%) received postoperative radiotherapy, but only $23(2 \%)$ received adjuvant radiotherapy. Of those with positive margins specifically, 244 (31\%) received postoperative radiotherapy, and again only 19 $(2.4 \%)$ received adjuvant radiotherapy. We compared our radiotherapy utilization rates with the literature (Table 4). ${ }^{34-38}$

Of all patients treated with RP, $270(12 \%)$ were seen within 6 months of their RP. Of the patients with adverse RP pathology (positive margins, ECE or SVI), 230 (23\%) were seen within 6 months of their RP. Of the 793 patients with positive margins, 198 (25\%) were seen within 6 months of their RP; of these patients, 129 (65\%) received radiotherapy (15\% truly adjuvant and $85 \%$ salvage radiotherapy), and 69 (35\%) did not. Of the 69 patients seen within 6 months of their RP by an oncologist and did not receive radiotherapy, $50(72 \%)$ were truly eligible for adjuvant radiotherapy (as defined above); of these, 20 (40\%) patients were advised against adjuvant radiotherapy by the oncologist.

Logistic regression for factors correlating with the use of postoperative radiotherapy included age (as a categorical variable), ECE status, SVI, positive margin status, Gleason score, and drive time to a cancer centre. A statistical significance $(p<0.005)$ in ECE, margins status, SVI and Gleason score was correlated with use of postoperative radiotherapy. The use of postoperative radiotherapy was higher for patients with higher grades (39\% for Gleason 8-10 cases vs. 8\% for Gleason $6>$ cases), SVI (51\% with vs. $12 \%$ without), ECE (33\% with vs. $10 \%$ without), and involved margin $(31 \%$ with vs. $6 \%$ without) ( $p$ values all $<0.0001$ with Chi Square tests). Due to the small number of cases receiving truly adjuvant radiotherapy, no regression was performed for adjuvant radiotherapy specifically.

\section{Discussion}

The use of postoperative radiotherapy in our series $(15 \%)$ is lower than expected based on the prevalence of adverse pathologic factors $(47 \%)$. This implies that postopera-

\begin{tabular}{|c|c|c|c|c|c|}
\hline Study & Site & No. RP procedures & Positive margin (\%) & Positive ECE (\%) & Positive SVI (\%) \\
\hline Schreiber et al. (2010) & SEER & 35642 & $18.3 \%^{\dagger}$ & 12.3 & 4.4 \\
\hline \multirow[t]{3}{*}{ Bhojani et al. (2009) } & Creteil & 839 & & 28 & 14.5 \\
\hline & Milan & 225 & & 11.1 & 5.3 \\
\hline & Partin & 5730 & & 22 & 3 \\
\hline Bianco et al. (2005) & & 1746 & 12 & 20 & 10 \\
\hline Blute et al. (2001) & & 2518 & 39 & 34 & 15 \\
\hline Boorjian et al. (2008) & & 7591 & 33 & & \\
\hline Eskicorapci et al. (2004) & & 1043 & & 24.2 & 10.3 \\
\hline Karakiewicz et al. (2005) & & 5831 & 26.7 & 34.7 & 11.2 \\
\hline Karakiewicz et al. (2008) & & 1838 & & 26.9 & 5.5 \\
\hline Palisaar et al. (2008) & & 1343 & 19.6 & & \\
\hline Quinn et al. (2001) & & 732 & 45.9 & $42.8^{*}$ & 13.1 \\
\hline Swanson et al. (2007) & & 715 & 18.0 & 24.10 & 8.80 \\
\hline Swindle et al. (2005) & & 1389 & 12.9 & & \\
\hline \multirow{2}{*}{ Walz et al. (2009) } & Hamburg & 2911 & 21.4 & 21.50 & 12.60 \\
\hline & Cleveland & 2875 & 29.3 & 26.3 & 8.6 \\
\hline Ward et al. (2004) & & 7268 & 38.0 & & \\
\hline Wright et al. (2010) & SEER Database & 65633 & 21.2 & & \\
\hline Average of all studies & & & 26.4 & 24.8 & 9.8 \\
\hline BCCA total prostate cases $2005-2007$ & & 2181 & 36.3 & 21.6 & 9.0 \\
\hline
\end{tabular}


Tyldesley et al.

\begin{tabular}{|c|c|c|c|c|c|c|c|c|}
\hline \multirow[t]{2}{*}{ Study } & \multirow[t]{2}{*}{ No. RP } & \multicolumn{7}{|c|}{ Positive surgical margins by pathological stage } \\
\hline & & pT2 overall (\%) & pT2a (\%) & pT2b (\%) & pT3 overall (\%) & pT3a (\%) & pT3b (\%) & pT4 (\%) \\
\hline Swindle et al. (2005) & 1389 & 6.8 & & & & 23 & & \\
\hline Palisaar et al. (2005) & 1343 & 10.6 & & & 30.5 & 26.7 & 36.7 & 44.4 \\
\hline Guillonneau et al. (2003) & 1000 & 15.5 & 6.9 & 18.6 & 31.5 & 30 & 34 & \\
\hline Orvieto et al. (2006) & 996 & 1.7 & & & 25.3 & 24.2 & 27.1 & \\
\hline Salomon et al. (2003) & 538 & 17.8 & & & & & & \\
\hline Cohn et al. (2002) & 382 & & & & 34.8 & 39 & 12.5 & \\
\hline Martinez-Pineiro et al. (2006) & 604 & 19.2 & & & 53.2 & & & 75 \\
\hline Average of all studies & & 11.9 & 6.9 & 18.6 & 35.1 & 28.6 & 27.6 & 59.7 \\
\hline BCCA total prostate cases $2005-2007$ & 2181 & 30 & & & 57 & & & \\
\hline
\end{tabular}

RP: radical prostatectomy; BCCA: British Columbia Cancer Agency.

tive radiotherapy, particularly adjuvant radiotherapy, was underutilized in $\mathrm{BC}$ during the study era, but was similar to rates of postoperative radiotherapy in other published series (Table 4). This potential under-utilization of adjuvant radiotherapy may reflect a lack of awareness of the data or a perception that the benefit of adjuvant radiotherapy is not worth the additional morbidity. Given the lack of definitive data supporting an overall survival benefit during the era of this study, the latter is most likely the main factor. It is also possible that the use of adjuvant radiotherapy has increased since the additional data on survival was published in 2009. ${ }^{4}$ The main use of radiotherapy in our series was salvage for relapse (as opposed to adjuvant radiotherapy), and the main predictors of its use, as expected, were Gleason grade, ECE, $\mathrm{SVI}$ and involved margins.

The presence of positive margins is considered one of the main drivers for postoperative adjuvant radiotherapy; therefore, the prevalence of positive margins warrants particular attention. The positive margin rate $(36 \%)$ in our study was similar to the population-based rate found in Ontario (which ranged from $0-53 \%) .{ }^{11}$ It is difficult to compare these rates to studies that are not population-based, as there may be selection bias, however, the results are within the range of published series $(18 \%-46 \%$, with a mean of $31 \%$ ) (Table 2). A large population-based series from the Surveillance, Epidemiology and End Results (SEER) registry reported an overall margin positive rate of $21 \%{ }^{39}$

The positive margin rate for $\mathrm{pT} 2$ patients in our series (of $30 \%$ ) exceeded the $20 \%$ threshold held by most Ontario urologists. ${ }^{11}$ However, the positive margin rates for pathologic T2 patients in British Columbia are generally comparable to the range of regional rates seen in Ontario $(16 \%-42 \%),{ }^{11}$ although they are higher than those seen in other jurisdictions (Table 2). The positive margin rate in British Columbia in pT3 cases $(57 \%)$ are also comparable to the range of regional rates seen in Ontario (42\%-83\%), ${ }^{11}$ and within the ranges of rates reported in the literature $(24 \%$ $80 \%) .{ }^{13-29}$ In comparison to the recent large SEER series,

\begin{tabular}{|c|c|c|c|c|}
\hline \multirow[t]{2}{*}{ Study } & \multirow[b]{2}{*}{ Study (Memorial Sloan-Kettering } & \multirow[t]{2}{*}{ Number of RP } & \multicolumn{2}{|l|}{ Number receiving postoperative RT (\%) } \\
\hline & & & & \\
\hline \multirow[t]{2}{*}{ Stephenson et al. (2009) } & $\begin{array}{c}\text { Cancer Center and Baylor College } \\
\text { of Medicine 1987-2005) }\end{array}$ & 6398 & $115(2)$ & \\
\hline & $\begin{array}{c}\text { Validation (Cleveland Clinic and } \\
\text { University of Michigan) }\end{array}$ & 6279 & $538(8)$ & \\
\hline \multirow{2}{*}{ Berge et al. (2007) } & \multirow{2}{*}{ SEER Database } & \multirow{2}{*}{3940} & Adjuvant (<6 months) & $281(7.1)$ \\
\hline & & & Follow-up (6-66 months) & $283(8.1)$ \\
\hline Moreira et al. (2009) & $\begin{array}{l}\text { Veteran Affairs Medical Centers } \\
\text { 1998-2008. }\end{array}$ & 1975 & Salvage RT (including patients on ADT) & $220(11)$ \\
\hline Macdonald et al. (2008) & \multirow{2}{*}{ CaPSURE (1989-2004) } & 4563 & Salvage RT (>6 months, detectable PSA) & $237(5.2)$ \\
\hline Macdonald et al. (2007) & & 5336 & Adjuvant (<6 months) & $96(1.8)^{*}$ \\
\hline Schreiber et al. (2010) & SEER Database & 35642 & Adjuvant (<12 months) & $1186(11 \%)^{\dagger}$ \\
\hline \multirow{2}{*}{\multicolumn{2}{|c|}{ BCCA total prostate cases 2005-2007 }} & \multirow{2}{*}{2181} & Adjuvant ( $<6$ months, with undetectable PSA) & $23(2)^{* *}$ \\
\hline & & & Salvage & $267(26)^{* *}$ \\
\hline
\end{tabular}


Need for, and use of, post prostatectomy radiotherapy

our margin positive rates exceed those reported for SEER (18\% for pT2, and $44 \%$ for pT3). ${ }^{39}$ Unlike the SEER study, which was also population-based, our study detailed patient data on postoperative PSA, which allowed us to distinguish adjuvant and early salvage radiotherapy. The perioperative mortality rate in British Columbia is well within the accepted target described by Cancer Care Ontario (CCO) $(<1 \%)$ and those reported in the literature $(0-0.5 \%) .{ }^{39}$

There are a few caveats and potential limitations in our analysis. Pre-treatment stage and risk groupings were not available for many of the prostatectomy cases, and this limited our ability to estimate the extent to which higher risk patients received RP. Therefore, the margin status findings for the preoperative consensus risk groups may be biased; the referred cases with relapsing PSAs may be over-represented. We also had the potential for missing some cases with the fact that registry ascertainment was not $100 \%$ (but this was very minimal). A few cases from eastern regions of British Columbia may get their radiotherapy in Alberta and these patients would not be captured; however, these are sparsely populated regions and would not have a significant impact on the overall radiotherapy utilization rates.

There may be important intraobserver variations in the reporting of positive margins and pathologic stage among pathologists in British Columbia. Only one urologist was performing laparoscopy robotic prostatectomy during this study era, with relatively few cases; therefore, a learning curve related to robotic laparoscopic prostatectomy would not have been a factor. We lack data on patient preferences, decision-making discussions with urologists, and documentation of comorbidities for patients who had a RP and were not referred to a cancer centre. However, we believe that most patients were assessed by a radiation oncologist. In our analysis only patients who received radiotherapy within 6 months of prostatectomy for an undetectable postoperative PSA in the absence of androgen ablation were considered truly adjuvant. This very strict definition of adjuvant radiotherapy may be one reason the proportion of patients receiving it is low. However, even if we extended the time for adjuvant therapy to 12 months post-prostatectomy, the overall adjuvant radiotherapy rate post-prostatectomy was only $1.7 \%$; for those with positive margins specifically, it was only $3.4 \%$. There is ongoing debate whether the benefit of adjuvant radiotherapy would be as significant in the current era compared to early salvage radiotherapy.

\section{Conclusion}

We encourage all urologists to consider early referral (within 6 months of surgery) to a radiation oncologist for consideration of adjuvant radiotherapy in the setting of high-risk features (ECE, positive margins or SVI) on pathology after RP. Urologists should discuss the risks and benefits of adju- vant radiotherapy and discuss enrolment in the RADICALS (Radiotherapy and Androgen Deprivation In Combination After Local Surgery) trial ${ }^{40}$ or other similar trials.

Competing interests: Dr. Tyldesley is a Michael Smith Foundations for Health Research Scholar. This study was funded by an ACURA grant from the Canadian Association of Radiation Oncology. This paper was presented at Canadian Association of Radiation Oncology Annual Meeting in Vancouver, September 2010.

This paper has been peer-reviewed.

Acknowledgements: The authors thank Rosa Zetler, Moninder Vaid, and Maggie Payne for their assistance with data abstraction.

\section{References}

1. Bolla M, Van Poppel H, Van Cangh P, et al. Does post-operative radiotherapy (P-RXT) after radical prostatectomy (Px) improve progression-free survival (PFS) in pT3N0 prostate cancer (PC)? (EORTC 22911). J Clin Oncol (Meeting Abstracts) 2004;14S:4504.

2. Wiegel T, Bottke D, Willich N, et al. Phase III results of adjuvant radiotherapy (RT) versus wait and see? (WS) in patients with pT3 prostate cancer following radical prostatectomy. J Clin Oncol 2005; 16S:4513.

3. Thompson I, Tangen C, Lucia M, et al. Adjuvant radiotherapy for pathologic T3 prostate cancer: results of a randomized, prospective clinical trial with metastasis-free survival endpoint. J Urol 2005; 173:A451-52.

4. Thompson I, Tangen C, Paradelo J, et al. Adjuvant Radiotherapy for Pathological T3NOMO Prostate Cancer Significantly Reduces Risk of Metastases and Improves Survival: Long-Term Followup of a Randomized Clinical Trial. J Urol 2009;181:956-62. http://dx.doi.org/10.1016/i.juro.2008.11.032

5. Van der Kwast T, Bolla M, Van Poppel H, et al. Identification of Patients With Prostate Cancer Who Benefit From Immediate Postoperative Radiotherapy: EORTC 22911. J Clin Oncol 2007;25:4178-86. http:// dx.doi.org/10.1200/JC0.2006.10.4067

6. Wiegel T, Bottke D, Steine U, et al. Phase III Postoperative Adjuvant Radiotherapy After Radical Prostatectomy Compared With Radical Prostatectomy Alone in pT3 Prostate Cancer With Postoperative Undetectable Prostate-Specific Antigen. J Clin Onc 2007;27:2924-30. http://dx.doi.org/10.1200/ JC0.2008.18.9563

7. Chin J. Salvage versus adjuvant radiotherapy after radical prostatectomy: argument for adjuvant radiotherapy. Can Urol Assoc J 2009;3:241-4.

8. Izawa J. Salvage radiotherapy after radical prostatectomy. Can Urol Assoc J 2009;3:245-50.

9. Pickles T, Morgan S, Morton G, et al. Adjuvant radiotherapy following radical prostatectomy: Genito-Urinary Radiation Oncologists of Canada Consensus Statement. Can Urol Assoc J 2008;2:95-9.

10. Sia $M$, Pickles $T$, Morton $G$, et al. Salvage radiotherapy following biochemical relapse after radical prostatectomy: proceedings of the Genito-Urinary Radiation Oncologists of Canada consensus meeting. Can Urol Assoc J 2008;2:500-7.

11. Chin J, Srigley J, Mayhew L, et al. Guideline for optimization of surgical and pathological quality performance for radical prostatectomy in prostate cancer management: evidentiary base. Can Urol Assoc J 2010;:13-25.

12. Lukka H, Warde P, Pickles T, et al. Controversies in prostate cancer radiotherapy: consensus development. Can J Urol 2001;8:1314-22.

13. Karakiewicz P, Eastham JA, Graefen M, et al. Prognostic Impact of Positive Surgical Margins in Surgically Treated Prostate Cancer. Urology 2005;66:1245-50. http://dx.doi.org/10.1016/i.urology.2005.06.108

14. Bhojani N, Salomon L, Capitanio U, et al. External Validation of the Updated Partin Tables in a Cohort of French and Italian Men. Int J Radiat Oncol Biol Phys 2009;73:347-52. http://dx.doi.org/10.1016/i. iirobp. 2008.04.082

15. Karakiewizz PI, Bhojani N, Capitanio U, et al. External Validation of the Updated Partin Tables in a Cohort of North American Men. J Urol 2008; 180:898-902. http://dx.doi.org/10.1016/i.juro.2008.05.044

16. Boorijan SA, Karnes RJ, Rangel $\mathrm{U}$, et al. Mayo Clinic Validation of the D'Amico Risk Group Classification for Predicting Survivial Following Radical Prostatectomy. J Urol 2008;179:1354-60. http://dx.doi. org/10.1016/i.juro.2007.11.061 
Tyldesley et al.

17. Eskicorapci SY, Karabulut E, Türkeri L, et al. Validation of 2001 Partin tables in Turkey: a multicenter study. Eur Urol 2005; 47:185-9.

18. Chan E0, Groome PA, Siemens DR. Validation of quality indicators for radical prostatectomy. Int I Cancer 2008;123:2651-7. http://dx.doi.org/10.1002/iic.23782

19. Quinn DI, Henshall SM, Haynes AM, et al. Prognostic Significance of Pathologic Features in Localized Prostate Cancer Treated With Radical Prostatectomy: Implications for Staging Systems and Predictive Models. J Clin Oncol 2001;19:3692-705.

20. Swanson GP, Riggs M, Hermans M. Pathologic findings at radical prostatectomy: Risk factors for failure and death. Urol Oncol 2007;25:110-4. htrp://dx.doi.org/10.1016/j.urolonc.2006.06.003

21. Walz J, Chun FK, Klein EA, et al. Nomogram Predicting the Probability of Early Recurrence After Radical Prostatectomy for Prostate Cancer. J Urol 2009;181:601-7. http://dx.doi.org/10.1016/i. juro.2008.10.033

22. Blute ML, Bergstralh EJ, locca A, et al. Use of Gleason Score, Prostate Specific Antigen, Seminal Vesicle and Margin Status to Predict the Biochemical Failure after Radical Prostatectomy. I Urol 2001;165:119-25. http://dx.doi.org/10.1097/00005392-200101000-00030

23. Schreiber D, Rineer J, Yu JB, et al. Analysis of pathologic extent of disease for clinically localized prostate cancer after radical prostatectomy and subsequent use of adjuvant radiation in a national cohort. Cancer 2010;116:5757-66. http://dx.doi.org/10.1002/cncr.25561

24. Stephenson AJ, Kattan MW, Eastham JA et al. Prostate Cancer-Specific Mortality After Radical Prostatectomy for Patients Treated in the Prostate-Specific Antigen Era. J Clin Onc 2009;27:4300-5.

25. Palisaar RJ, Noldus J, Graefen $M$, et al. Influence of nerve-sparing (NS) procedure during radical prostatectomy (RP) on margin status and biochemical failure. Eur Urol 2005;47:176-84.

26. Swindle $P$, Eastham JA, Ohori M, et al. Do margins matter? The prognostic significance of positive surgical margins in radical prostatectomy specimens. J Urol 2005; 174:903-7.

27. Ward JF, Zincke H, Bergstralh EJ, et al. The impact of surgical approach (nerve bundle preservation versus wide local excision) on surgical margins and biochemical recurrence following radical prostatectomy. J Urol 2004;172(4 Pt 1):1328-32.

28. Wright IL, Dalkin BL, True LD, et al. Positive surgical margins at radical prostatectomy predict prostate cancer specific mortality. I Urol 2010;183:2213-8.
29. Guillonneau B, elFettouh $\mathrm{H}$, Baumert $\mathrm{H}$, et al. Laparoscopic radical prostatectomy: oncological evaluation after 1,000 cases a Montsouris Institute. J Urol 2003;169:1261-6.

30. Orvieto MA, Alsikafi NF, Shathav AL, et al. Impact of surgical margin status on long-term cancer control after radical prostatectomy. BJU Int 2006;98:1199-203.

31. Salomon L, Anastasiadis AG, Antiphon P, et al. Prognostic consequences of the location of positive surgical margins in organ-confined prostate cancer. Urol Int 2003;70:291-6.

32. Cohn JH, El-Galley R. Radical prostatectomy in a community practice. I Urol 2002;167:224-8.

33. Martínez-Piñeiro L, Cáceres F, Sánchez C, et al. Learning Curve of Laparoscopic Radical Prostatectomy in a University Teaching Hospital: Experience after the First 600 Cases. Eur Urol Suppl 2006;5:914-24. http://dx.doi.org/10.1016/i.eursup.2006.07.018

34. Stephenson AJ, Scardino PT, Eastham JA, et al. Postoperative nomogram predicting the 10-year probability of prostate cancer recurrence after radical prostatectomy. J Clin Oncol 2005;23:7005-12.

35. Berge V, Thompson T, Blackman D. Additional surgical intervention after radical prostatectomy, radiation therapy, androgen-deprivation therapy, or watchful waiting. Eur Urol 2007;52:1036-43. Epub 2006 Dec 12.

36. Moreira DM, Jayachandran J, Presti JC Jr, et al. Validation of a nomogram to predict disease progression following salvage radiotherapy after radical prostatectomy: results from the SEARCH database. BJU Int 2009;104:1452-6. http://dx.doi.org/10.1111/i.1464-410X.2009.08623.x

37. Macdonald OK, D'Amico AV, Sadetsky N, et al. Predicting PSA failure following salvage radiotherapy for a rising PSA post-prostatectomy: from the CaPSURE database. Urol Oncol 2008;26:271-5. Epub 2007 Dec 3.

38. Macdonald OK, D'Amico AV, Sadetsky N, et al. Adjuvant radiotherapy in prostate cancer: predictors of prostate-specific antigen recurrence from the CaPSURE database. Urology 2007;70:106-10.

39. Sura S, Schreiber D, Wortham A, et al. Patterns of Care in High Risk Radical Prostatectomy Patients: The SEER Cohort. Int J Rad Onc Biol Phys 2009;75:S311.

40. Radicals Trial. httrp://www.radicals-trial.org/default.aspx Accessed March 23, 2012.

Correspondence: Dr. Scott Tyldesley, British Columbia Cancer Agency, Vancouver, BC V5Z 4E6; fax: 604-877-0505; styldes@@bccancer.bc.ca 